\title{
Human Ecological Complexity: Epistemological Implications of Social Networking and Emerging Curriculum Theories
}

\author{
DONALD L. GILSTRAP \\ Wichita State University (USA)
}

\begin{abstract}
This article explores the growing use of social networking among contemporary students and researchers in education. It is argued that social networking systems exhibit many of the characteristics of complex systems, such as self-organization and far-from-equilibrium conditions. This article, therefore, contends that curriculum development in the near future will be deeply impacted by social networks. Equally, curriculum scholars are in a unique position to integrate chaos and complexity theories which help to recreate the ontological and epistemological frameworks needed to respond to social networking phenomena.
\end{abstract}

\section{Introduction}

Online courseware and social networking have dramatically changed the way students and educators learn and think about learning and scholarly communication. With a transdisciplinary ecological focus on educational research, this article incorporates research in chaos and complexity theories, sociology, and philosophy to address major research questions drawn from the American Educational Research Association [AERA] 2010 Annual Meeting in relation to social networks and human ecological complexity. Epistemologically, social networking sites challenge traditional forms of knowledge inquiry, because they are organic in nature. Rather than identifying discrete units of knowledge for acquisition in the teaching and learning process, knowledge creation is 
emergent in these networks, where participants appear to play the roles of selforganizing system agents. Equally, we see challenges to traditional higher education in the forms of far-from-equilibrium environments through wide scale budget cuts and competition from for-profit companies, educational software, and online certifications. In some ways, we might even ask if these far-from-equilibrium conditions contribute to the mass appeal of social networking among college students which paradoxically and simultaneously drive new developments in curriculum theories.

As it stands now, social networks appear to display features of chaotic systems in regards to teaching and learning, given the absence of a meaningful gestalt for integrating both the technology and subsequent emergent phenomena into our philosophical discussions. This article, therefore, contends that curriculum theory is deeply impacted by social networks, whether realized or not in the classroom. However, this article also argues that curriculum theory is in a unique position to integrate chaos and complexity theories which help to recreate the ontological and epistemological frameworks needed to respond to social networking phenomena.

\section{Theoretical framework}

Facebook-and MySpace, and Twitter, and whatever we're stampeding for next-are just the latest stages of a long attenuation. They've accelerated the fragmentation of consciousness, but they didn't initiate it. They have reified the idea of universal friendship, but they didn't invent it. (Deresiewicz, 2009).

This article draws on the theoretical framework of ecological complexity, focusing on the sociology of teaching and learning through emergent forms (Bateson, 1972/2000; Doll, 1993). Where Bateson found metaphorical bridges between that which happens in the ecological world and that which happens in human lives, human ecology seeks to describe populations of societal coalescence around different sociological constructs. The term human ecological complexity, therefore, is intended to bring these constructs together while focusing specifically on social networking communities as the population under study.

It is also important to state early on in this article that the term "networks" is not a new philosophical construct, resulting from rapid technological changes. Certainly human networks emerged during the socialization of clan dynamics in pre-historic life and will continue into the future (White \& Johansen, 2005). And human technological networks have existed since the first tools were used to communicate ideas and exchanges across time and space. However, just as each of these revolutions led to new forms of expression, so have the tools of social networking led to chaotic and complex forms of observing and describing human ecological complexity. While embracing the humanistic elements of technology, Jenks and Smith (2006) contend in their own analysis of human network dynamics, "it would be more accurate and more respectful to say that our society and its technology has availed itself of one of the most enduring topographies of Nature and has thereby reinvented itself" (p. 266). 
Davis (2004) aptly points out there is some confusion regarding the differences between environmentalism and ecology. The former deals with concern for the environment while the latter expands the environmental view to incorporate concomitant intersubjective and interobjective relationships between life forms (Davis, Sumara, \& Luce-Kapler, 2000). "Intersubjectivity is an epistemology of the social construction of reality, knowledge, and humanistic interpretivism;" how the observer constructs reality in relation to ontology (Gilstrap, 2009, p. 4; Davis, 2004). At the same time interobjectivity, "seeks out qualitative spatial representations of interconnectedness" in an ontology of interacting relationships (Gilstrap, 2009, p. 4; Davis, 2004). Whereas Davis presents this epistemological paradox graphically through a visual metaphor of a tree of life with intertwined branches of intersubjectivity and interobjectivity, this same metaphor is carried over into scholarly citation analyses from the internationally known journal Nature. When viewing the interconnected relationships between disciplines in the life sciences, pure and applied, subjective and objective, evolutionary and positivist, a curious visual representation [Image 1] unfolds very similar to the epistemological framework Davis presents. Expanding this to global complexity, Urry (2003) argues, "it is not that the sum is thought to be greater than the size of its parts as in some formulations. It is rather that the system effects are different from its parts" (p. 77). It is perhaps here that we find a basis for an emergent ontology of human ecological complexity. "The global and the local are inextricably and irreversibly bound together through a dynamic relationship, with huge flows of 'resources' moving backwards and forwards between the two" (Urry, 2003, p. 84). And in social network graphing, analysis software such as Sentinel Visualizer highlights the complex web of connections that emerge from a teaching and learning environment focused on human ecological complexity [Image 2].

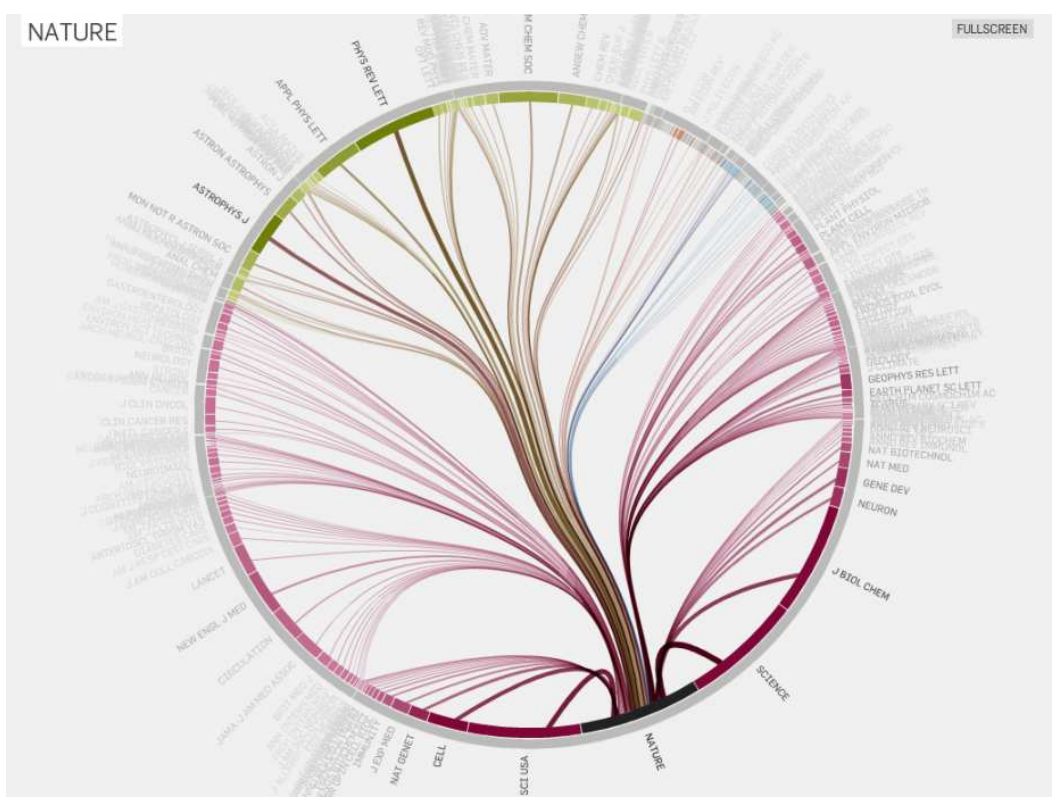

Image 1 - Visual Representation of Eigenfactor Metrics of Citation Analyses in Nature (http://well-formed.eigenfactor.org/img/shots/radial 06.png) 


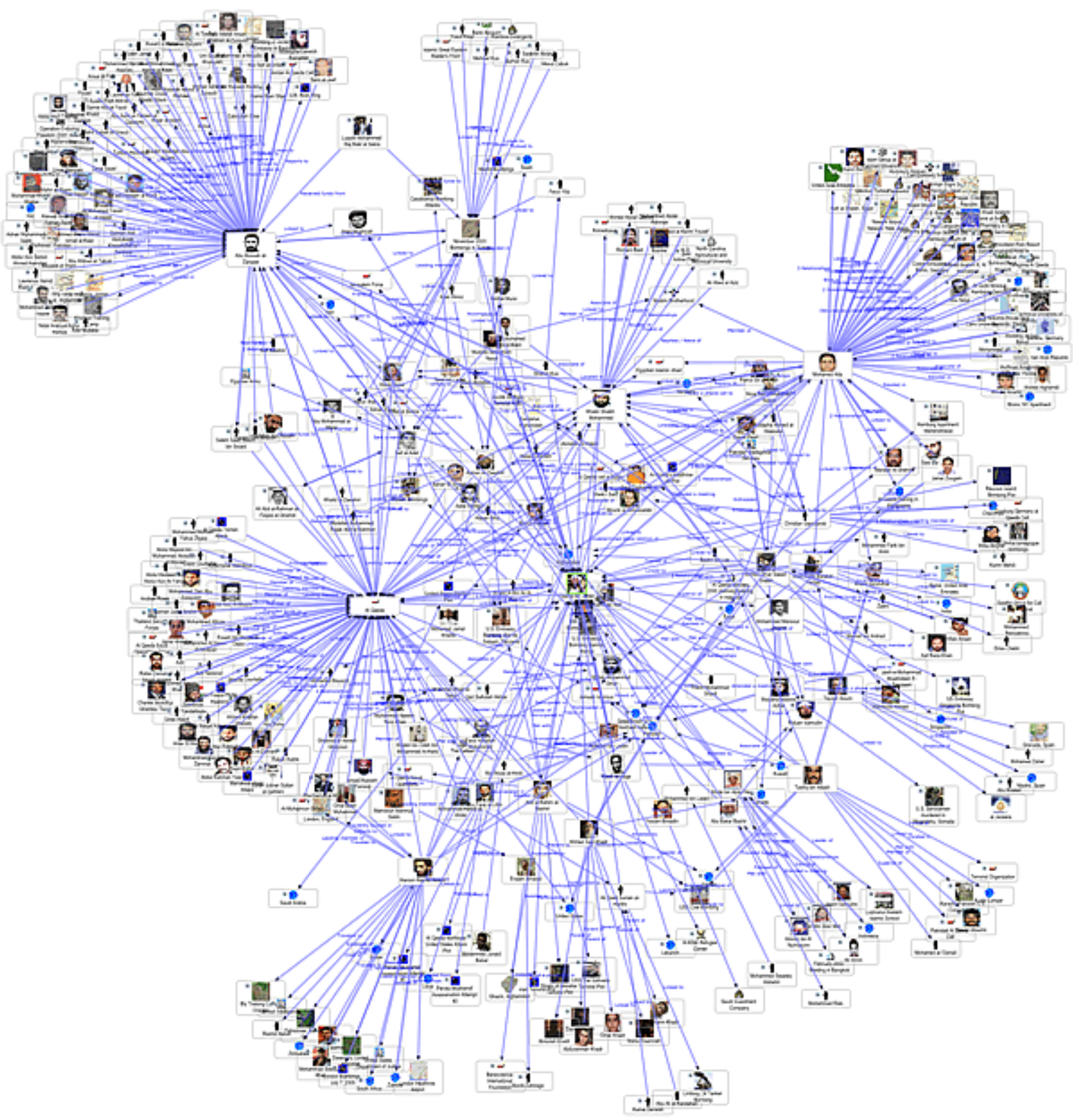

Image 2 - Social Networking Graph (Sentinel Visualizer, 2010).

As a result of the increasing use of networked technology in teaching and learning, these emerging phenomena exhibit characteristics of chaos and complex systems. In general, the World Wide Web is difficult over which to impose control, and there is no central management or deus ex machina. Human networks arise and disappear spontaneously in a self-organizing manner, similar to the self-organized criticality in the physical world described by Bak (1996). When viewed through a reductionist lens, these 
are disparate and isolated systems. However, when viewed through the lens of complexity, these systems take on entirely new forms of interconnections and interrelationships when attempting to see them from the micro level. Moreover, a more general ecology of global complexity emerges as geographic borders and social demarcations begin to disappear. The metaphors of the physical world, therefore, take on new meaning as our teaching and learning shift "from the stationary, wooden, fixed 'desk' occupied by the individual scholar (even with chained books in the medieval period), to the ephemeral, mobile and interchangeable 'desktop' that can be occupied by anyone" (Urry, 2003).

In effect, the world of information is not only similar to the world of matter and energy, in many ways it exhibits fluid and dynamic characteristics that go beyond the boundaries of the physical object in human systems (Materana \& Varela, 1991; Hayles, 1999; Smith \& Jenks, 2006). However, Urry (2003) warns that we should not apply the lens of autopoeisis to human ecologies, because it is this functional naming of the system that lends to a logical conclusion that 'global functionalism' (p. 101) is an immediate byproduct of the autopoeitic state of global meaning making. If the autopoeitic description of ecological complexity is not robust enough, is another theoretical construct such as complex dissipative structures a stronger descriptive framework?

The relationships between technology and humans lead us closer to an ontology of human ecological complexity. As Smith and Jenks (2006) argue:

Our post-humanism is decidedly not of the kind that sees the cyborg as the emancipation of the human, but rather as the opening of a specific relationship between the technological and the human... The car, telephone, mobile phone, computers and the internet do not so much 'free' us as demand qualitatively new structural changes in the relationships of human ecology... Our emphasis requires that ontology cannot be assimilated under epistemology... We confront a downhill process towards inexorable equilibrium and a downhill process towards complex eco-auto-organisation (Smith \& Jenks, pp. 257-58, 262).

So developing an ontology for human ecological complexity will require a movement away from Heidegger's (1973) absorption of ontology into epistemology. The future of curriculum theory will rely on the co-evolution of ontologies and epistemologies which highlight the robustness of social networks. It is not the intent of the post-modern to reject and destroy the modern, but rather to bring the modern along with it (Doll, 1993).

More specifically, course management and social networks exhibit unique characteristics of human ecological complexity. Social network sites can be defined "as web-based services that allow individuals to (1) construct a public or semi-public profile within a bounded system, (2) articulate a list of other users with whom they share a connection, and (3) view and traverse their list of connections and those made by others within the system" (Boyd \& Ellison, 2007). Course management software with which many of us are familiar--such as Blackboard, WebCT, and Desire2Learn--can be viewed to some extent as social network systems closed from their external environment due to authentication restrictions in technology where only enrolled students and teachers have 
access to the content and its creation. In effect, the student has little or no control over the boundary conditions of the social network. However, group based learning applications and discussion forums in course management software do not limit students and teacher to a proscribed learning time frame and environment, as well as the psychological constraints imposed by the "traditional" classroom setting. Consequently, an environment emerges where teaching and learning have the potential ${ }^{1}$ to exhibit self-organized criticality in thinking and understanding. And more importantly, how do traditional classroom settings place rigid boundary conditions on teaching and learning that limit this potential for human ecological complexity? If we can speculate that our students have more readily embraced social networks than online courseware, we might also ask if social networks are, therefore, better suited to facilitate self-organization?

When looking at social networks, I would like to call attention to historical analysis of research literature in combination with autobiographical and observation research, utilizing the online application Facebook as one example. Certainly there is plethora of social network technologies that currently exist and are too numerous to describe in detail in the confines of this article. MySpace was one of the original social network sites that has evolved mainly into a network of shared music among a dominant age group of mid-adolescents (Wilkinson \& Thelwall, 2010). Twitter is described as a microblogging community, particularly focusing on short snippets of daily life, and, more specifically, consumer advocacy and product branding (Jansen, Zhang, Sobel, \& Chowdury, 2009). Its impact is global in scope, but its retention of users suffers from high mortality due to lack of long-term interest while it is equally limited in its ability to promote collaboration (Honey \& Herring, 2009; Java, Finin, Song, \& Tseng, 2007). And tertiary networks like Flickr have focused primarily on communities of image creators and users with subsequent photographic tagging (Rorissa, 2010).

Facebook originated among university students, has the broadest global demographics, the widest scope and impact (Wiklinson \& Thelwall, 2010), and therefore seems to be a germane social network for connecting the adult learning community with an ontology for teaching and learning in general terms. The founder of Facebook, Mark Zuckerberg, even describes the technology through a construct for global learning:

People are increasingly discovering information not just through links to web pages but also from the people and things they care about. This flow of social information has profound benefits - from driving better decisions to keeping in touch more easily... We think that the future of the web will be filled with personalized experiences. (Zuckerberg, 2010).

This social network in teaching and learning exhibits many of the characteristics found in course management software; however, it extends the view of human

\footnotetext{
${ }^{1}$ My emphasis on potential might reflect our own dilemmas within this teaching environment. As we struggle to move away from mediums of exchange that highlight physical classroom settings, we sometimes wander [wonder] around in search of catalysts that elicit chaotic and complex interactions in social networks.
} 
ecological complexity in many more ways. Granted, countless hours might be wasted by students on sophomoric quizzes, questionable personality inventories, and games created to collect market intelligence. Yet, in addition to these seemingly valueless elements, in the Facebook environment knowledge creation and dissemination, relationships and interconnectivity, shared understanding and intersubjectivity, and group dialogue are driven by users in textual and audio-visual forms. Self-organization and the hypercritical state are marked features of this medium of communication with online dialogues that manifest a higher-order emergence of complex group system states of understanding.

Why is this important? If we draw attention to the most recent activity from the U.S. Department of Education, Arne Duncan, the current U.S. Secretary of Education has put forward a new National Education Technology Plan 2010. Focusing on five main points, this technology plan "calls for revolutionary transformation rather than evolutionary thinking," which seems to coordinate advantageously for chaos and complexity curriculum theorists. Calling attention to the specific sections on learning and teaching:

Learning - The model of $21^{\text {st }}$ century learning... calls for engaging and empowering learning experiences for all learners... It brings state-of-the-art technology into learning to enable, motivate, and inspire all students, regardless of background, languages, or disabilities, to achieve. It leverages the power of technology to provide personalized learning instead of a one-size-fits-all curriculum, pace of teaching, and instructional practices.

Teaching - The model of $21^{\text {st }}$ century learning calls for using technology to help build the capacity of educators by enabling a shift to a model of connected teaching. In such a teaching model, teams of connected educators replace solo practitioners and classrooms are fully connected to provide educators with $24 / 7$ access to data and analytic tools as well as to resources that help them act on the insights the data provide. (DoE, 2010, pp. $\mathrm{v}$-ix).

Numerous and large data sets have been collected already by researchers in the social and behavioral sciences, using analyses of social interaction in Facebook. As examples, researchers from Harvard and UCLA collect and analyze data to address issues of homogeneity and heterogeneity in human development. Researchers at Indiana, Northwestern, Penn State, Tufts, and UT-Austin challenge traditional sociological and psychological theories when they are imposed on social networking (Rosenbloom, 2007). And we might also question the limitations of Facebook when seeking out an ontology for human ecological complexity. We problematize investigations of ecology in educational research, since "furthering one's ecological advantage, as nature and history show us, is often at the expense of another [individual]" (Smith \& Jenks, 2006, p. 269). Certainly the most poignant aspect of the networked world leaves us questioning how those who teach and learn without appropriate or open technologies might fall further into ecological disadvantage, while political and economic aspects of global complexity can contribute to growing inequalities in worldwide classrooms. 
When questioning the roles of human ecological complexity in global education, our greatest challenges will be to traverse political and social hegemonies that prevent the emergence of a framework for learning ecologies. Furthermore, warnings from Bateson (1972/2000) in the cybernetic and Prigogine (2000) in the networked world demand our scrutiny: "as the population becomes more networked, there may be an opposite effect: the imperatives of the connected collective overwhelm the individual's ability to make choices" (p. 36; Prigogine and Stengers, 1984). Extending this view, the human ecology of Facebook may reflect in-person relationships; regardless of the number of friends one has on Facebook, intimate interactions take place with a smaller number of people (Economist, 2009). Subsequently, an epistemology of human ecological complexity will most certainly require simultaneous critiques of both heterogeneous and homogeneous relationships that arise from social networks in teaching and learning circles.

\section{Method}

As the AERA 2010 Call for Submissions pointed out, there are methodological challenges to studies that investigate complex ecologies. And certainly these issues have been debated in Complicity for a number of years. This article seeks out ontological and epistemological frameworks of human ecological complexity in learning and teaching through chaotic and complex technological social networks. Data sources for this article are, therefore, primarily both theory and case driven from the research literature and through the use of observation and autobiographical investigation of social network phenomena by this author. An interpretive framework of chaos and complexity theories is used to transmute the propositions of human ecological complexity in social networks. Consequently, this use of multiple methods is subjective and specific to this researcher. The discussion that follows is not intended to be a generalization of social networking in educational circles. Rather, my hope is that this analysis serves somewhat as a prolegomena for further discussion among the chaos and complexity research community.

\section{Discussion}

Faculty share a history of demonizing students' extracurricular activities (Greek organizations and rock and roll concerts were once favorite targets.) Currently faculty are, by turns, befuddled and horrified at the hold that Facebook and other social networking sites have on students. (Eiodice \& Gaffin, 2008, p. 1).

Several of us might laugh when we read this quote, but the working reality of the pervasiveness of social networking among college students demands more scrutiny in learning and teaching circles. In their study of undergraduate Zoology students' use of Facebook, Eiodice and Gaffin (2008) found a high correlation between the number of photos in which students were tagged in relation to high academic performance. This implies that students who are more intimately networked among peers, and who are subsequently more human ecologically complex, tend to be higher academic achievers. Conversely, the higher number of Facebook applications in use by a particular student 
highly correlated with low academic performance. My personal observations reinforce the latter finding in this study. Social networking sites are replete with applications that, when analyzed through a framework of educational settings, seem to have no real value. These applications range from personality tests to "what color are you," and have no real validity or reliability as testing measures. They are primarily created by marketing firms to gain access to user data, thereby creating a method for customized marketing for the Facebook user. In effect, they can be described as limiting attractors that move system agents towards static and controlled system influences. There are a few applications, like Farmville that, in theory, seem to promote basic principles of social responsibility, time and resource management, and problem solving. Applications such as these may hold little value in formal educational settings, but it is curious that so many of our students spend time on these applications, sometimes at the expense of their academic lessons (Grabmeier, 2009). Moreover, have we as educators missed opportunities to promote in our own teaching circles formats for learning in which students readily engage already? Do we have opportunities to capture student engagement in learning away from carefully crafted marketing firms when competing for their time? Certainly concepts such as social responsibility, time and resource management, and problem solving are philosophical constructs with which we can agree.

Eodice and Gaffin (2008) suggest that misguided stereotypes about different types of Facebook use among students do not correlate to performance in the classroom. "We believe it possible that heavy Facebook users are also effective multi-taskers" (p. 4). And therein lies the rub: the advent of social networking manifests the multi-tasking culture pervasive among contemporary undergraduate students. Although arguments are occasionally made about the negative aspects of multi-tasking, Bluedorn and Jaussi (2007) contend that polychronicity, "a preference for dealing with multiple tasks simultaneously" (p. 200), is a cultural dimension of socio-psychological analyses that contributes neither positively nor negatively to task accomplishment when taken by itself. Rather, when the environment is designed to enhance polychronicity, contemporary students will tend to excel in learning. As opposed to monochronicity, which is single task-oriented and subsequently linear, polychronicity implies increasing complexity with more simultaneous connections within a person's learning environment and interactions with people. A few propositions developed by Bluedorn and Jaussi for organizational learning might also carry over into our own learning communities and help determine success in social networks:

The more polychromic a person, the better the person's performance will be on tasks characterized by high skill variety.

The greater the extent to which individuals have the opportunity to perform work in a manner consistent with their preferences for how polychronically they prefer to work, the greater their job satisfaction will be.

The greater an individual's polychronicity, the more job satisfaction the person will experience when performing unstructured tasks. 
The level of autonomy on the job will moderate the relationship between polychronicity and creativity such that when autonomy is high, polychronicity will be positively correlated with creativity, but when autonomy is low, polychronicity will either be less strongly correlated with creativity or not correlated with it at all.

The more organic an organization's structure, the more polychromic its culture will be. (Bluedorn and Jaussi, 2007, pp. 190-193).

This may be the dilemma with which we are faced when designing curriculum for newer generations of students: as educators, we very well may be part of the problem that contributes to poor learning outcomes. If we focus our curriculum designs on linear and proscribed methods of teaching, then those students who are more adapted to polychronicity environments will tend to perform at lower levels of prescribed expectations. And then it will be far too easy to fall back complacently on the mantra, "what is the matter with students today?!"

Take the cases where social networking is applied in ways that do promote ecological consciousness in society. The current U.S. presidential administration utilizes Facebook and Twitter profusely to disseminate information and garner feedback from constituents (Economist, 2010). Social Psychology Network has also partnered with Twitter to recruit participants in empirical research studies from its user base (Psych_Studies, 2010), diverting average students away from market driven social networking applications and toward scholarly applications. And the National Science Foundation has partnered with Microsoft Corporation for archiving and access features for researchers to the Azure data cloud (Johnston, 2010). And virtually every wellknown national scholarly or professional organization has a presence in one or more of the social networking sites. A simple search on Facebook for your organization of choice will most likely confirm this statement. Even as I write this article, I find myself perplexed in my ability to cite properly and with full recognition of the Web 2.0 sources used for this research. Although these resources are mainstreamed, several of them exist in forms and mediums that are outside of the traditional boundaries of stylistic manuals. Does this reinforce how traditional scholarship is constrained by linear models that adversely contribute to our own relevance in the future of teaching and learning in the global environment?

We might equally draw attention to issues of time as a construct in learning, particularly in light of introducing polychronicity into human ecological complexity. Prigogine (1996) showed the importance of recognizing ontologically the existence of the arrow of time and that by seeking out this understanding, the illusion of time in reversible systems begins to be shadowed by the irreversibility of time. Likewise, it might be argued that pushing students toward monochronicity can, effectively, be promoting the linearity inherent in reversible systems. Time as a philosophical construct has been explored in curriculum theories, ranging from how the arrow of time contributes to our understanding of irreversibility in critical reflection processes (Gilstrap, 2010) to how effectively teams and individuals within teams work together based on their preference for polychronicity (Conte, 2007). Does the linear course model conflict with the emergent 
phenomena of social networks, and does this paradox challenge us to think about the irreversibility of time in new ways?

Each of these cases highlight the role of new educational and scholarly mediums that promote complex systems in human interaction and, moreover, provide an emerging framework for human ecological complexity in teaching and learning. But what are the potential negative bifurcations that can emerge from social networks in global complexity? As Diresiewicz (2009) notes:

They call them social-networking sites for a reason. Networking once meant something specific: climbing the jungle gym of professional contacts in order to advance your career. The truth is that Hume and Smith were not completely right. Commercial society did not eliminate the self-interested aspects of making friends and influencing people, it just changed the way we went about it. Now, in the age of the entrepreneurial self, even our closest relationships are being pressed onto this template. (Deresiewicz, 2009).

Returning paradoxically to Facebook's Farmville, the negative bifurcation of this application described even as an "ecosystem... a self-reinforcing downward cycle" (Arrington, 2009), is that the real-world potential to exploit its users in order to gain market shares and further ad revenues is a much stronger basin of attraction than the theoretical proposition to promote ecology and social responsibility. These types of negative bifurcations leave us with challenging questions when considering social networking technologies as human ecologically complex curriculum tools. How much time is actually wasted on non-valid applications designed solely for marketing purposes and subsequent add revenue generation? How do these mediums of communication affect critical reflection processes that may emerge more readily in more intimate and face-to-face learning environments? How do social networks challenge the academy's predefined concepts of learning and can they lead to a lack of rigor, status, and credibility? And how do we recognize and balance students' changing learning needs from entertainment? These questions should help guide our continuing dialogue on the evolution of an ontology for global complexity.

Human ecological complexity in social networks moves us away from many of the boundary conditions of physical spaces. National lines become gray while issues of power hegemony in less-than-free societies become harder to control. In this way, the self-organized criticality of social networks will lead far-from-equilibrium systems toward chaotic bifurcation points in the transmutation of knowledge creation and diffusion. Scholarly research will move from the reductionist framework of specification toward multidisciplinary research involving multiple methods and interpretations of phenomena. An epistemological framework for human ecological complexity should demand the next phase in creating new knowledge: seeking out transdisciplinary studies where we transcend disciplinary knowledge through an integrative ecology of understanding and how we participate in the process of educational research. In Image 3 , we see evidence of this very concept in an information metrics map of scholarly citation analysis. When visualized, the connections between such disciplines as sports medicine, resource management, and physics elicit simultaneous skepticism and curiosity. Since this phenomenon is already taking place in the research community, 
either by intent or serendipity, should we not explore this in the development of future curriculum theories?

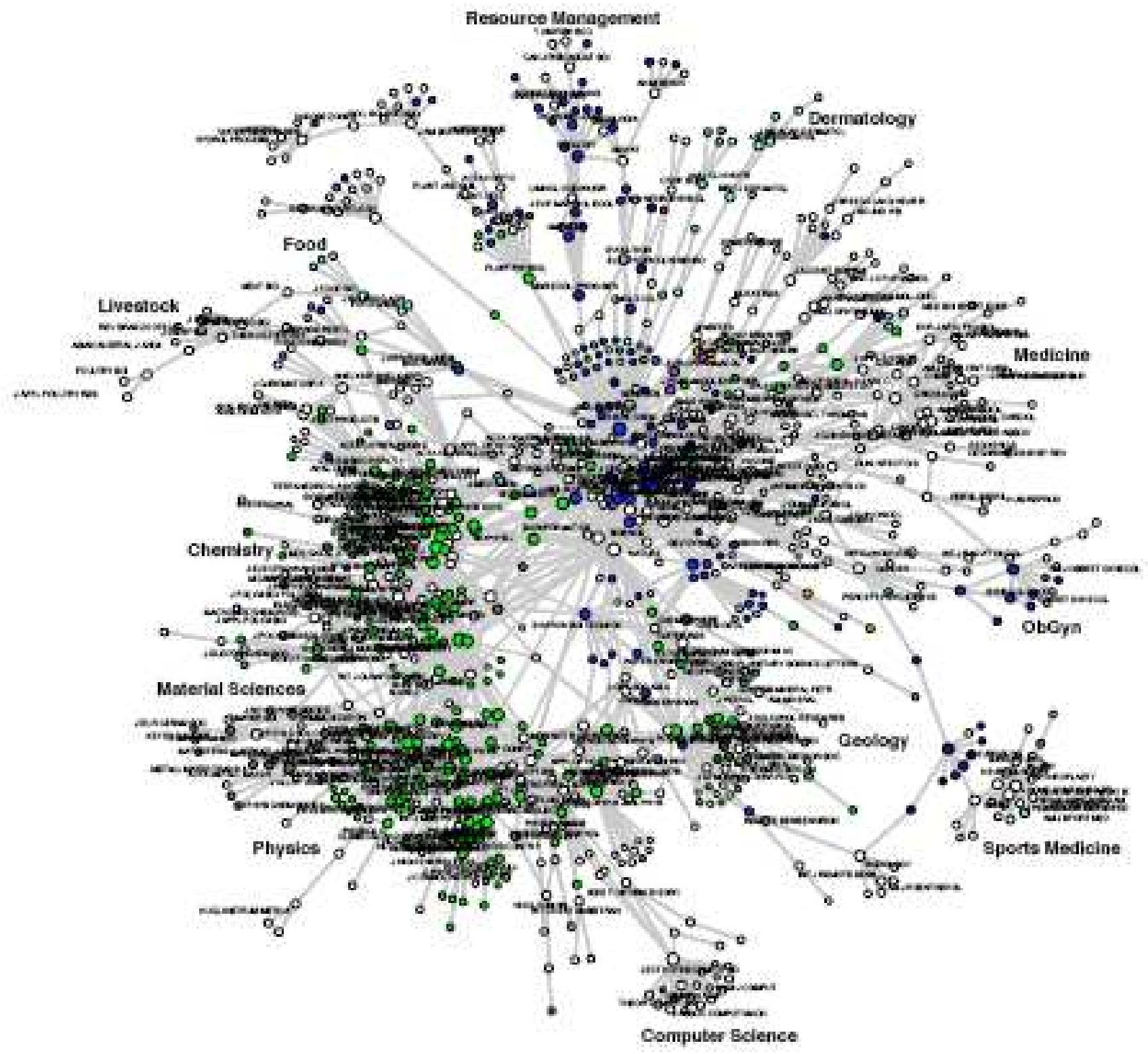

Image 3 - Visualization of Transdisciplinary Research Citations (Bollen, Van de Sompel, and Rodriguez, 2008).

Learning and teaching in a framework of human ecological complexity then must consider different ontologies that describe more readily a rapidly changing and farfrom-equilibrium environment. No longer will homomorphic philosophies that perpetuate the closed and near-equilibrium structures of group dynamics suffice in a world of global complexity. When looking at Image 4, we see the absence of linearity in group interactions with simultaneous boundary conditions. The isomorphic Markov chain highlights the nonlinear aspects of integrating social networks in the curriculum 
design. As we seek out an ontology of human ecological complexity in curriculum theory, therefore, we will need to investigate how we can integrate isomorphic complexity into our views and descriptions of the simultaneous and paradoxical dualisms of structure preservation and symmetry breaking.

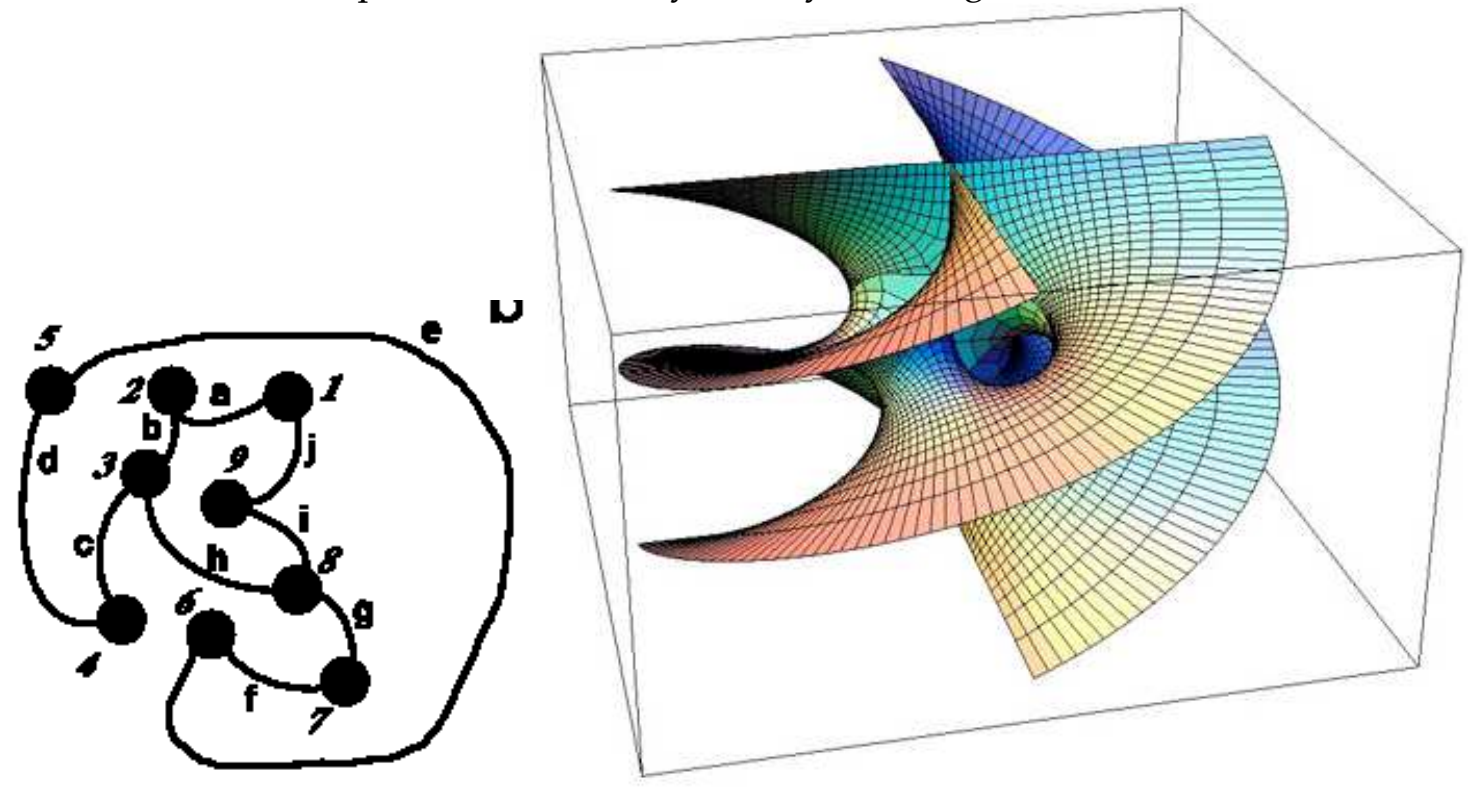

Image $4-2$ and 3 dimensional visualizations of isomorphic group ecologies in teaching and learning

\section{Conclusion}

The emergence of social networks challenges us to look for new forms of educational research that incorporate human ecological complexity. Certainly, chaos and complexity theories provide a lens for interpreting these phenomena in transdisciplinary and methodological ways that come closer to describing such a complex ecology. However, this "recreation" of ourselves in a transformed, technological, and global world demands even more complex investigations of ontological and epistemological frameworks for understanding human ecology in teaching and learning environments. Yet where do we go from here? Are significant theories outside of chaos and complexity already extant but underutilized? Can we build upon network analysis theory in ethnography (White \& Johansen, 2005)? Are ecological frameworks proposed by Bateson (2000/1972) foundational for exploring human ecological complexity? Do scholars such as Vygotsky (1978; Jörg, 2009) seek similar responses for teaching and learning during rapid non-linearity? Do the vital simultaneities of Davis and Sumara (2006) already address an epistemology for understanding these phenomena? And how can we draw more specifically from the works of chaos and complexity theorists in educational research such as Doll (1993) and Fleener (2002) to help further develop ontological and epistemological frameworks for creating and re-creating curriculum theories that respond more readily to social networks? 
This article challenges basic assumptions in educational research, suggesting that many educational theories in use are not strong enough to address the philosophical implications of human ecological complexity in social networks. Granted, researchers in other connected theories might make this same argument, from critical theory and existentialism to post-modernism and post-structuralism. Interpretation of social network phenomena through the lens of chaos and complexity theories helps guide this study in the creation of a new ecological framework of teaching and learning that addresses the ontologies and epistemologies of the AERA 2010 Annual Meeting theme. I do not choose to define human ecological complexity specifically or attempt to propose a prescription for its further development in educational theory within the confines of this article. However, it is anticipated that further discussion of these concepts among Complicity scholars will lead to extended dialogues among educational researchers and practitioners in general on the roles of human ecological complexity in future research.

\section{References:}

(Feb. 26, 2009). Primates on Facebook: Even online, the neocortex is the limit. Economist. Retrieved April 1, 2010, from: http://www.economist.com/sciencetechnology/displayStory.cfm?story id=13176775

(Jan. 28, 2010). A world of connections: Online social networks are changing the way people communicate, work and play, and mostly for the better. Economist. Retrieved April 1, 2010 from: http://www.economist.com/specialreports/displayStory.cfm?story id=15351002.

Arrington, M. (2009). Scamville: The social gaming ecosystem of hell. Tech Crunch (October 31). Accessed December 1, 2010, at: http://techcrunch.com/2009/10/31/scamville-the-social-gamingecosystem-of-hell/.

Bak, P. (1996). How Nature Works: The Science of Self-Organized Criticality. New York: Copernicus.

Bateson, G. (2000/1972). Steps to an Ecology of Mind. Chicago: University of Chicago Press.

Bluedorn, A. C. and Jaussi, K. S. (2007). Dimensions of time across levels of analysis. In: Dansereau, F., \& Yammarino, F. J. (Eds.), Multi-Level Issues in Organizations and Time (Vol. 6). New York: Elsevier, pp. 187-223.

Bollen, J., Van de Sompel, H. and Rodriguez, M. A. (2008). Towards usage-based impact metrics: First results from the MESUR project. Paper presented at the Joint Conference on Digital Libraries, ACM and IEEE, June 16-20, Pittsburgh, PA.

boyd, d. m. and Ellison, N. B. (2007). Social network sites: Definition, history, and scholarship. Journal of Computer-Mediated Communication, 13(1). Retrieved December 1, 2011, from: http://jcmc.indiana.edu/vol13/issue1/boyd.ellison.html

Conte, J. M. (2007). Measuring temporal constructs across multiple levels of analysis. In: Dansereau, F., \& Yammarino, F. J. (Eds.), Multi-Level Issues in Organizations and Time (Vol. 6). New York: Elsevier, pp. 225-235.

Dansereau, F., \& Yammarino, F. J. (Eds.). (2007). Multi-Level Issues in Organizations and Time (Vol. 6). New York: Elsevier.

Davis, B. (2004). Inventions of teaching: A genealogy. Mahwah, NJ: Lawrence Erlbaum Associates, Publishers.

Davis, B., Sumara, D., \& Luce-Kapler, R. (2000). Engaging minds: Learning and teaching in a complex world. Mahwah, NJ: Lawrence Erlbaum Associations.

Davis, B., \& Sumara, D. (2006). Complexity and Education: Inquiries into Learning, Teaching, and Research. Mahwah, NJ: Lawrence Erlbaum Associates. 
Deresiewicz, W. (Dec. 6, 2009). Faux friendship. The Chronicle Review. Accessed March 30, 2010 at: http://chronicle.com/article/Faux-Friendship/49308/.

Doll, W. E., Jr. (1993). A Post-Modern Perspective on Curriculum. New York: Teachers College, Columbia University.

Eodice, M. and Gaffin, D. (2008). Let's face Facebook. The National Teaching \& Learning Forum, 17(6), 14.

Gilstrap, D. L. (2010). Critical reflection as an irreversible process: Epicurus, the Arrow of Time, and an ontology for organizational learning phenomena. Emergence: Complexity and Organization, 12(4), 95117.

Gilstrap, D. L. (2009). Collective case study method and fractal geometry: Instrumental and intrinsic cases in organizational research. Emergence: Complexity and Organization, 11(4), 1-14.

Grabmeier, J. (April 8, 2009). Study finds link between Facebook use, lower grades in college. Research Communications. Ohio State University. Accessed January 1, 2011 at: http://researchnews.osu.edu/archive/facebookusers.htm

Heidegger, M. (1973/2003). The end of philosophy. Chicago: University of Chicago Press.

Honey, C. and Herring, S. C. (2009). Beyond microblogging: Conversation and collaboration via Twitter. In: Proceedings of the $42^{\text {nd }}$ Hawaii International Conference on System Sciences, pp. 1-10. IEEE. Accessed December 1, 2010, at: http://ieeexplore.ieee.org/stamp/stamp.jsp?tp=\&arnumber $=4755499 \&$ isnumber $=4755314$

Jansen, B. J., Zhang, M., Sobel, K., and Chowdury, A. (2009). Twitter power: Tweets as electronic word of mouth. Journal of the American Society for Information Science and Technology, 60(11): 2169-2188.

Java, A., Finin, T., Song, X., and Tseng, B. (2007). Why we Twitter: Understanding microblogging usage and communities. In: Proceedings of the 9th WebKDD and 1st SNA-KDD 2007 workshop on Web mining and social network analysis, pp. 56-65. Association of Computing \& Machinery. Accessed December 1, 2010, at: http://portal.acm.org/citation.cfm?id=1348556.

Johnston, S. J. (Feb. 4, 2010). Microsoft offers free use of Azure to NSF. Internetnews.com. Retrieved April 1, 2010, from: http://www.internetnews.com/government/article.php/3863136/Microsoft+Offers+Free+Use+ of +Azure+to+NSF.htm

Jörg, T. (2009). Thinking in complexity about learning and education: A programmatic view. Complicity: An International Journal of Complexity and Education, 6(1), 1-22.

Prigogine, I. (2000). The future is not given, in society or nature. NPQ: New Perspectives Quarterly, 17(2), 35-37.

Prigogine, I., \& Stengers, I. (1984). Order Out of Chaos: Man's New Dialogue with Nature. New York: Bantam Books, Incorporated.

Psych_Studies (2010). Retrieved April 1, 2010 from: http://twitter.com/Psych Studies

Rorissa, A. (2010). A comparative study of Flickr tags and index terms in a general image collection. Journal of the American Society for Information Science and Technology, 61(11): 2230-2242.

Rosenbloom, S. (Dec. 17, 2007). On Facebook, scholars link up with data. New York Times. Retrieved July 1, 2009, from: http://www.nytimes.com/2007/12/17/style/17facebook.html? r=1

Sentinel Visualizer (2010). FMS Advanced Systems Group. Accessed January 3, 2011, at http://www.fmsasg.com/SocialNetworkAnalysis/

Smith, J., \& Jenks, C. (2006). Qualitative Complexity. New York: Routledge.

Transforming American education: Learning powered by technology (2010). from http://www.ed.gov/sites/default/files/NETP-2010-final-report.pdf.

Urry, J. (2003). Global Complexity. Cambridge, UK: Blackwell.

Vygotsky, L. 1978. Mind in society. Cambridge MA: Harvard University Press.

White, D. R., \& Johansen, U. (2005). Network Analysis and Ethnographic Problems: Process Models of a Turkish Nomad Clan. Oxford, UK: Lexington Books. 
Wilkinson, D. and Thelwall, M. (2010). Social network site changes over time: The case of MySpace. Journal of the American Society for Information Science and Technology, 61(11): 2311-2323.

Zuckerberg, M. (April 21, 2010). Building the social web together. The Facebook Blog. Accessed December 1, 2010, at: http://blog.facebook.com/blog.php?post=383404517130.

\begin{abstract}
About the Author
Donald Gilstrap is Professor of Educational Leadership and Dean of University Libraries at Wichita State University, 1845 Fairmount Street, Wichita, KS, USA. His research and scholarship includes complexity theory in leadership and organizational dynamics, assessment of learning, and nonlinear dynamics during organizational change. He can be reached via email at donald.gilstrap@wichita.edu.
\end{abstract}

(C) Copyright 2011. The author, DONALD L. GILSTRAP, assigns to the University of Alberta and other educational and non-profit institutions a non-exclusive license to use this document for personal use and in courses of instruction provided that the article is used in full and this copyright statement is reproduced. The author also grants a non-exclusive license to the University of Alberta to publish this document in full on the World Wide Web, and for the document to be published on mirrors on the World Wide Web. Any other usage is prohibited without the express permission of the authors. 